\title{
Evaluation of Effectiveness of New Infusion Set Equipped with an In-line Filter
}

\author{
Yoshinori Itoh ${ }^{* 1}$, Toshiaki Sendo ${ }^{2}$, Emi Nakatsune ${ }^{1}$, Yoshihiro Hirakawa', \\ Hiroaki Ikesue $^{1}$ and Ryozo Oishi ${ }^{1}$ \\ Department of Pharmacy, Kyushu University Hospital ${ }^{1}$ and \\ Department of Hospital Pharmacy, Okayama University Medical and Dental School ${ }^{2}$
}

$\left[\begin{array}{l}\text { Received April 7, } 2006 \\ \text { Accepted September 13, 2006 }\end{array}\right]$

In the present study, we evaluated the effectiveness of a new infusion set equipped with an in-line filter (5 $\mu \mathrm{m}$ pore size) in removing precipitates of foreign matter forming during or after the preparation of infusion fluids. We also examined the ability of the new infusion set to prevent adverse effects associated with the intravenous injection of fluids containing crystalline precipitates in rats. The number of particles and their sizes were measured for two infusion fluids administered using a conventional infusion set without an in-line filter and the new infusion set, collecting the samples for measurement from the outlets of the respective infusion sets. One of fluids was a glycyrrhizin solution prepared from a glass ampoule injection, and the other etoposide solution prepared by diluting a preparation of this solution in a vial with saline. A number of particles $(>10 \mu \mathrm{m}$ in size) were detected for both infusion fluids when administered by the conventional infusion set but none were detected in them when administered by the new infusion set. The intravenous injection of the precipitatecontaining etoposide solution from the conventional infusion set to rats caused marked extravasation of plasma proteins and edema in lungs. Such adverse reactions did not occur with the new infusion set, demonstrating that it was effective in removing particulate matter. It should thus be useful in intravascular fluid therapy from the safety point of view.

Key words — in-line filter, contamination, glass ampoules, etoposide deposit, pulmonary edema, rats,

\section{Introduction}

Quality control of infusion fluids is extremely important in the intravascular infusion therapy to avoid contamination of small particulates and the resultant occulusion of small blood vessels ${ }^{1}$. The contamination of particulates during or after preparation of infusion fluids occasionally provokes a serious health problem. The major sources of contamination of particulates are considered to be the glass fragments derived from glass ampoules ${ }^{2)}$ or the crystalline precipitates generated due to the low water solubility ${ }^{3)}$ or the incompatibility among mixed injectable medicines ${ }^{4)}$. A number of literatures have shown the serious adverse events related to the administration of the fluids containing small particulates ${ }^{5-8)}$. However, in most cases, it is not so easy to detect visually such small particulates in the infusion fluids. Therefore, the use of in-line filter is recommended to include in the intravenous drip line to avoid the potential risk of contamination of small particulates". A number of infusion sets equipped with an in-line filter are currently available but in most cases the filter is so fine as to remove bacteria and highly expensive. Therefore, the use of in-line filter in the infusion line is not necessarily common because of the medical expenses and the increase in the risk of infection.

The United States Pharmacopoeia (USP) provides that the upper limit of the number of particulates lager than $10 \mu \mathrm{m}$ in diameter is 25 particles $/ \mathrm{mL}$ in case of large volume injections $^{10)}$. On the basis of the criteria, Nipro Co. Ltd. has recently developed an infusion set equipped with an in-line filter of $5 \mu \mathrm{m}$ in pore size for the purpose of elimination of small particulates that generate during or after preparation of infusion fluids. The effective filtration area $\left(33 \mathrm{~mm}^{2}\right)$ of this filter is much smaller than that of the conventional sterilizing-grade filters (approximately $1000 \mathrm{~mm}^{2}$ ) thus less expensive. Moreover, the use of this new product has no risk of infection. In the present study, we evaluated the efficacy of this new infusion set to remove small particles contaminated during or after preparation of infusion fluids. We presented here the two representative cases of the contamination of particulates in the infusion fluids, the inclusion of exogenous particulates as well as the precipitation of endogenous crystalline substances, both of which are encountered in the routine prescription. We also tested whether the present infusion set prevent the pulmonary embolism occurred in rats after intravenous injection of the particulates- 
containing fluids.

\section{Methods}

\section{Chemicals}

The chemicals used in the present experiment were as follows : Stronger Neo-Minophagen $C^{\circledR}$ (SNMC) that contains $40 \mathrm{mg}$ glycyrrhizin in $20 \mathrm{~mL}$ solution in a glass ampoule (Lot No. ; 02074, Minophagen Pharmaceutical Co., Ltd, Tokyo), Lastet ${ }^{\circledR}$ injection containing $100 \mathrm{mg}$ etoposide, $400 \mathrm{mg}$ polysolvate $80,3 \mathrm{~g}$ macrogol citrate 400 and a small amount of ethanol (Lot No. ; X 41290, Nippon Kayaku Co., Ltd, Tokyo), and $500 \mathrm{~mL}$ Otsuka normal saline ${ }^{\circledR}$ (Lot No.; K $4 \mathrm{~K}$ 80, Otsuka Pharmaceutical Co., Ltd, Tokushima).

\section{Infusion sets}

The conventional intravenous infusion set with no in-line filter (Terufusion $^{\circledR}$, Lot No.; 971020 D 1) was purchased from Terumo Co. Ltd. (Tokyo). The new infusion set equipped with an in-line filter (Micro Check ${ }^{\circledR}$, Lot No.; 040806) was kindly donated from Nipro Co. Ltd. (Osaka), in which the filter was composed of the hydrophilic acrylate copolymer with $5 \mu \mathrm{m}$ pore size and $33.2 \mathrm{~mm}^{2}$ filtration area (Fig. 1).

\section{Animals}

Male Sprague-Dawley rats weighing 200-250 g (Kyudo Co., Saga) were used. The present experimental procedures were all approved by the Committee for the Care and Use of Laboratory Animals at the Faculty of Medicine, Kyushu University, and the law (No.105) and notification (No.6) of the Japanese government. All efforts were made to minimize animal suffering, and to reduce the number of animals used.

\section{Preparation of infusion fluids}

Based on the intended clinical application, five ampoules of SNMC $(20 \mathrm{~mL})$ were opened using ordinary cutter and then filled up in the empty bag of isotonic sodium chloride solution (100 mL, Otsuka Co. Ltd). Particle numbers in the glycyrrhizin solution were counted after collection of the prepared solution into the glass bottle through the infusion set. The etoposide injection ( $260 \mathrm{mg}$ etoposide in $13 \mathrm{~mL}$ ) was collected from a glass vial using a plastic syringe and added to $500 \mathrm{~mL}$ of $0.9 \%$ sodium chloride solution. At 0,2 , 3,4 and $5 \mathrm{~h}$ after dilution of etoposide solution, the fluid was collected into the glass bottle through the infusion set and the particle number was counted. For the measurement of particle counts in each drug solution, four or five batches were tested.

\section{Evaluation of the new infusion set}

Each infusion fluid was allowed to drip by gravity at the flow rate of $100 \mathrm{~mL} / \mathrm{h}$ through the conventional infusion set without in-line filter or the new infusion set equipped with an in-line filter. The infusion fluid was sampled into the particle-free glass bottle $(100 \mathrm{~mL})$ through the outlet of the respective intravenous infusion set and left to stand at room temperature for $10 \mathrm{~min}$ to remove air bubble. Sample collections were carried out in a laminar flow hood equipped with HEPA (high efficiency particulate air) filters. The efficiency of the new infusion set was evaluated by the following equation ${ }^{1)}$,

Particle removal efficiency $(\%)=(1-\mathrm{A} / \mathrm{B}) \times 100$

$$
\text { .............................(1), }
$$

where $\mathrm{A}$ and $\mathrm{B}$ represent the particle number in the fluids collected through the new infusion set and the conventional infusion set with no in-line filter, respectively.

\section{Measurement of the number of particulates}

Particulates in the intravenous fluid were counted using a PMS counter as described previously ${ }^{11}$. In brief, the PMS system consisted of an APSS-200 counter connected to a LiQuilaz-E 20 sensor with a laser diode $(121 \mathrm{~mW}, 780 \mathrm{~nm})$ and automatic bottle sampler, LS-200 (Particle Measuring Systems Inc., Boulder, CO, USA). The sample tube was inserted into the collected glass bottle, and the number of particulates larger than 2, 5, 10 and $25 \mu \mathrm{m}$ in size was counted. Data were obtained in triplicate determinations after discounting the first measurement.

\section{Determination of etoposide}

Etoposide injection $(260 \mathrm{mg}$ ) was diluted with $500 \mathrm{~mL}$ sa-

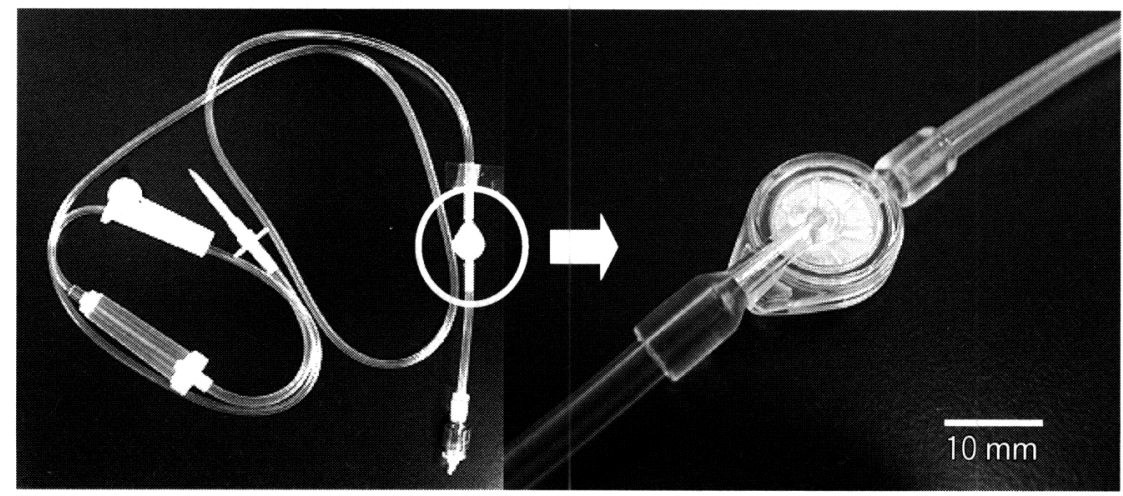

Fig. 1. Photographs of a New Infusion Set Equipped with an in-line Filter ( $5 \mu \mathrm{m}$ pore size). 
line (final concentration : $0.52 \mathrm{mg} / \mathrm{mL}$ ). At various intervals after dilution, the solution was collected to the glass bottle through the respective intravenous infusion set, and the concentration of etoposide was determined by the spectrophotometric detection with an O.D. at $282 \mathrm{~nm}$.

\section{Scanning electron microscopy}

A $100-\mathrm{mL}$ aliquot of the glycyrrhizin solution was filtered through a $0.45 \mu \mathrm{m}$ membrane (HA type ; Nihon Millipore, Tokyo) and the membrane was washed by delivering distilled water and dried in a petri slide. The filter membrane was imaged at $15 \mathrm{keV}$ using a scanning electron microscope (JSM-6360, JEOL DATUM Ltd., Tokyo).

\section{Measurement of pulmonary function after intravenous injection of precipitated etoposide solution in rats}

The pulmonary embolism was assessed by measuring the vascular permeability in lung tissues in rats, as described previously ${ }^{12)}$. Briefly, under anesthesia with sodium pentobarbital $(50 \mathrm{mg} / \mathrm{kg}$, i.p.), rats were injected with saline, solubilized or precipitated etoposide solution $(1 \mathrm{mg} / \mathrm{mL})$ at a dose of $5 \mathrm{mg} / \mathrm{kg}$ in combination with Evans blue dye (20 $\mathrm{mg} / \mathrm{kg}$ ) through the femoral vein. At $10 \mathrm{~min}$ after injection, the thorax was opened and the lung was perfused with physiological saline via a cannula inserted into the pulmonary artery to remove the intravascular Evans blue dye, then the lung parenchyma was dissected and weighed. Half of the dissected lung was immersed into formamide $(4 \mathrm{~mL} / \mathrm{g}$ wet weight of tissue) for $24 \mathrm{~h}$ to extract Evans blue. The remainder was dried in an oven at $60^{\circ} \mathrm{C}$ for $24 \mathrm{~h}$. The concentration of Evans blue was determined at $620 \mathrm{~nm}$ using spectrophotometric microplate reader (Immuno-mini, NJ-2300, Intermedical, Tokyo). The amount of the dye was calculated from the standard curve for Evans blue $(0.5-40 \mathrm{mg} / \mathrm{mL})$ and expressed as $\mu \mathrm{g}$ dye per $\mathrm{g}$ dry tissue weight.

\section{Determination of water, sodium and potassium contents in lung tissues}

To determine the water content and electrolytes concentrations in pulmonary tissues, rats were injected intravenously with saline or precipitated etoposide-containing solution, as described above. At $10 \mathrm{~min}$ after injection, lung tissues were placed on absorbent paper and adherent non-pulmonary tissues were carefully removed. Lungs were separated into lobes and the extra-lobar vessels were removed. During this procedure, care was taken to prevent passive bleeding and the discharge of tissue fluid from the lung. The wet and dry tissue weights were recorded and the water content (\%, $\mathrm{w} / \mathrm{w}$ ) was calculated as (wet weight-dry weight) $\mathrm{x} 100 /$ wet weight. The dried lobes were suspended in a mixture of nitric acid and perchloric acid $(2: 1, \mathrm{v} / \mathrm{v})$, homogenized, and then centrifuged at $1,000 \times \mathrm{g}$ for $10 \mathrm{~min}$. The resultant supernatant was diluted with distilled water. The concentrations of sodium and potassium were measured by an atomic absorption spectrophotometry (Model AA-6400 F, Shimadzu, Kyoto) using diluted standard solutions (Wako Pure Chemi- cals Inc., Osaka). Data obtained from triplicate assays were expressed as $\mathrm{mEq} / \mathrm{kg}$ dry tissue weight.

\section{Statistical analysis}

Data are expressed as the mean \pm SEM and statistically analyzed by one-way analysis of variance followed by Dunnett's test for multiple comparisons, or by paired t-test for comparison between two groups (Stat View; Abacus Concepts, CA). Statistical significance was defined as $\mathrm{P}<0.05$.

\section{Results}

\section{Efficacy of the new infusion set to remove small particu- lates}

Fig. $2 \mathrm{~A}$ shows the numbers of particulates larger than 2 , 5,10 , and $25 \mu \mathrm{m}$ in diameter containing in the glycyrrhizin solution collected through the conventional and the new infusion sets. Both the Japanese Pharmacopoeia (JP) and USP provide that the lower limit of the number of particles larger than $10 \mu \mathrm{m}$ in size is 25 counts $/ \mathrm{mL}$ in case of the large volume injections. The number of particles larger than $10 \mu \mathrm{m}$ in size in glycyrrhizin solution collected through the conventional infusion set was found to be $110 \pm 42$ counts $/ \mathrm{mL}$, which exceeds the lower limit provided by JP and USP. A scanning electron microscopic observation revealed that the particulates were mostly glass fragments (Fig. 2 B). On the other hand, the number of particulates larger than $10 \mu \mathrm{m}$ in size was dramatically reduced to $3 \pm 1$ counts $/ \mathrm{mL}$, a value that is within the lower limit provided by JP and USP, when the solution was collected through the new infusion set.

\section{Precipitates generation after dilution of etoposide solu- tion and the filtration efficacy of the new infusion set}

Among 5 etoposide solutions with different lot numbers, one sample showed a marked increase in the number of particulates larger than $10 \mu \mathrm{m}$ in size as early as $2 \mathrm{~h}$ after dilution and the number of particulates exceeded the lower limit provided by JP or USP (Fig. 3). The number of samples showing unacceptable counts of precipitates $(>10 \mu \mathrm{m}$ in size) was 2 and 3 at $3 \mathrm{~h}$ and $4 \mathrm{~h}$ after dilution, respectively. The numbers of particulates larger than $10 \mu \mathrm{m}$ and $25 \mu \mathrm{m}$ in sizes were $653 \pm 459$ and $199 \pm 159$ (mean \pm SEM, $n=5$ ) counts/mL, respectively, at $4 \mathrm{~h}$ after preparation. Subsequently, the filtration efficacy of the new infusion set was evaluated. The numbers of precipitates exceeding $10 \mu \mathrm{m}$ and $25 \mu \mathrm{m}$ in sizes were $1.2 \pm 0.4$ and $0.2 \pm 0.1$, respectively, after passing through the new infusion set (Fig. 4). Thus, the efficiencies of the present infusion set in removing particulates exceeding $10 \mu \mathrm{m}$ and $25 \mu \mathrm{m}$ in sizes were $99.8 \pm 0.1 \%$ and $99.4 \pm 0.5 \%$, respectively.

\section{Changes in etoposide content in filtrates collected at various intervals after dilution}

As shown in Fig. 5, the concentrations of etoposide in filtrates obtained within $3 \mathrm{~h}$ after dilution were not changed $(96.5 \pm 4.9 \%$ at $1 \mathrm{~h} ; 92.3 \pm 1.7 \%$ at $2 \mathrm{~h} ; 94.1 \pm 5.0 \%$ at 3 
A) Particulates counts

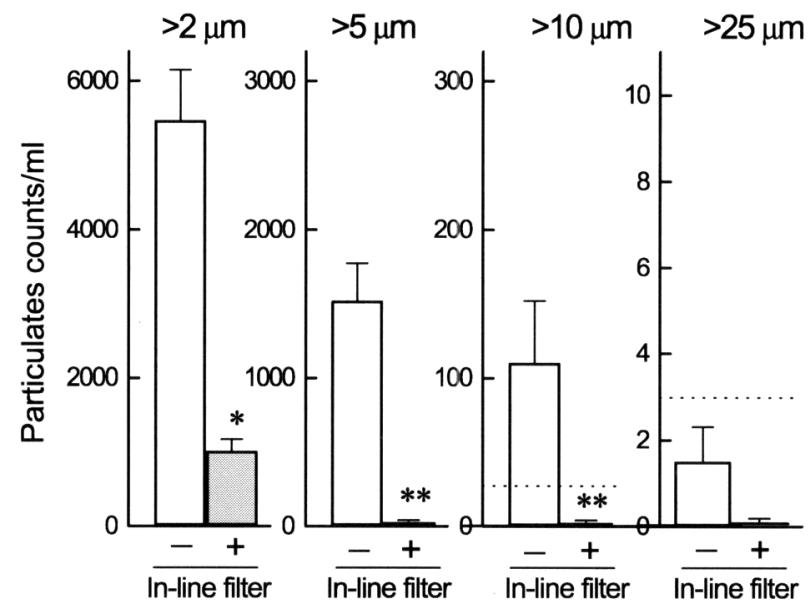

B) Scanning electron microscopic observations

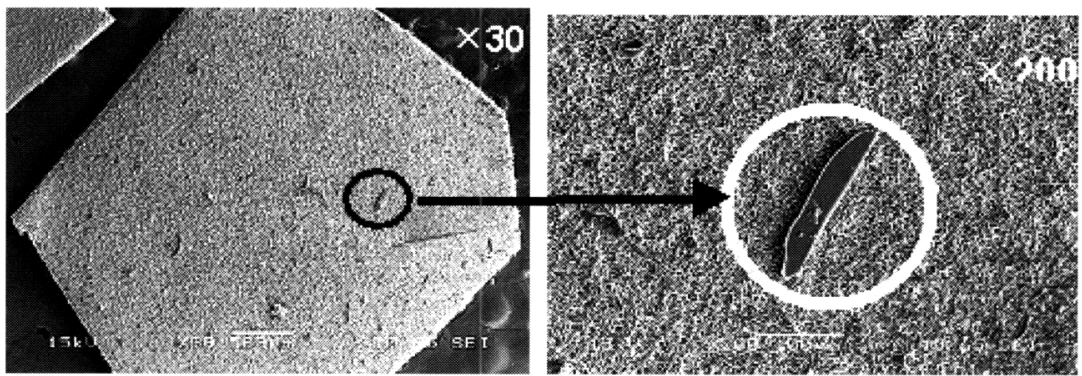

Fig. 2. Particulates Counts in the Injections Prepared from Glycyrrhizin Ampoule Injections $(100 \mathrm{~mL})$ and the Efficiency of the in-line Filter $(5$ $\mu \mathrm{m})$ to Remove Particulates (A) and Photographs of a Scanning Electron Microscope Showing Glass Fragments in the Glycyrrhizin Preparation (B). Open bar: non-filtered. Closed bar: filtered. The dotted line shows the JP or USP-defined limit of particulate counts in large volume injections. Data represent the mean \pm SEM $(n=4) .{ }^{*} \mathrm{P}$ $<0.05,{ }^{*}{ }^{*} \mathrm{P}<0.01$ vs.non-filtered (paired t-test).

$\mathrm{h}, \mathrm{N}=5$ ), however, the concentrations were significantly reduced at $4 \mathrm{~h}(86.2 \pm 3.5 \%, \mathrm{P}<0.05)$ and at $5 \mathrm{~h}(66.5 \pm 3.8$ $\%, \mathrm{P}<0.01)$ after dilution.

\section{Pulmonary edema observed after intravenous injection of precipitated etoposide solution in rats}

Intravenous injection of the precipitates-containing etoposide solution at a dose of $5 \mathrm{mg} / \mathrm{kg}$ caused a marked extravasation of plasma proteins in lungs of rats, as assessed by the leakage of protein-conjugated Evans blue dye into lung tissues (Fig. 6). The pulmonary extravasation was accompanied by the pulmonary edema, as shown by the increase in tissue water content. Moreover, the tissue concentration of sodium was significantly elevated, while that of potassium was significantly reduced, after injection of the precipitates-containing etoposide solution (Fig. 7). However, the intravenous injection of freshly prepared etoposide solution did not affect the vascular permeability, tissue water content or electrolytes contents (Figs. 6 and 7). It was notable that the etoposide solution did no longer cause pulmo- nary extravasation or edema, when it was passed through the present infusion set.

\section{Discussion}

In the present study, we demonstrated that the new infusion set equipped with an in-line filter efficiently removed the small particles contaminated in the infusion fluids.

Glycyrrhizin is widely used in Japan for the therapy of hepatic diseases, eczema, dermatitis and urticaria ${ }^{13)}$, and the commercial formulation ( $40 \mathrm{mg}$ ) is dispensed in $20 \mathrm{~mL}$ glass ampoules. The dose of glycyrrhizin is ranging from $40 \mathrm{mg}$ to $200 \mathrm{mg}$. In the present study, a number of particulates were found in glycyrrhizin solution prepared from 5 glassampoules, which exceeded the acceptable value provided by the JP and USP. A scanning electron microscopic observation indicated that the contaminated particulates were derived from glass ampoules. It has generally been considered that glass contamination occurs with high frequency in case of large ampoules ${ }^{14)}$. The contamination of glass fragments 

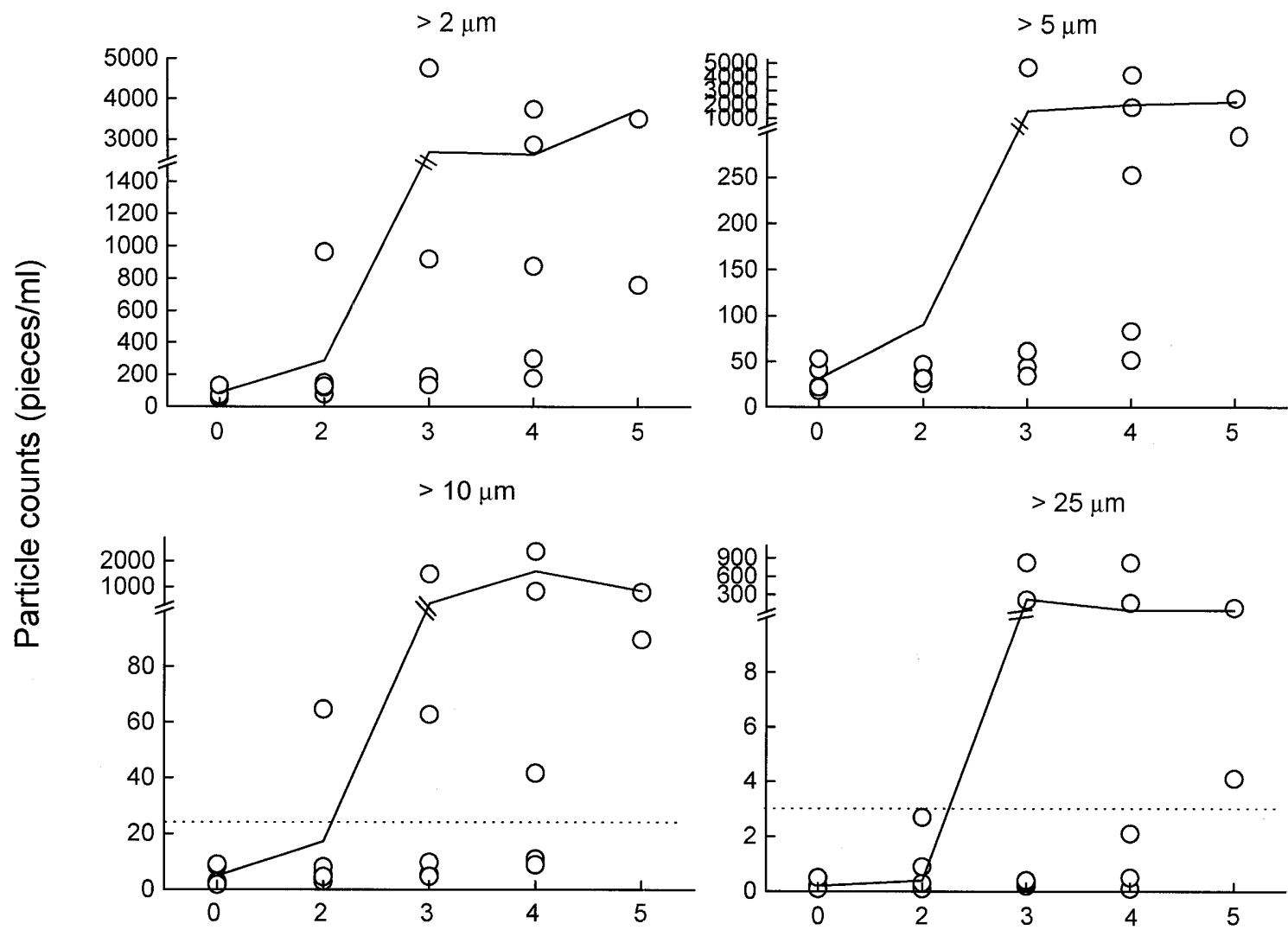

Time after dilution (hr)

Fig. 3. Time Course of Changes in the Number of Different Sizes of Precipitates Generated after Dilution of the Etoposide Injection with Saline. Data were obtained from 5 samples with different lot number and the average values were shown by a line graph.

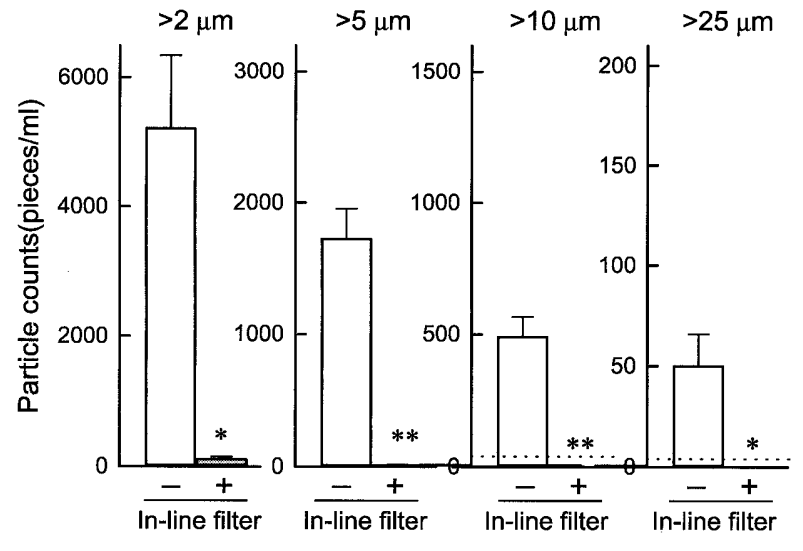

Fig. 4. Filtration Efficiency of the New Infusion Set Equipped with an in-line Filter $(5 \mu \mathrm{m})$ as Assessed at 5-6 h after Dilution of the Intravenous Etoposide Solution with Saline Solution. Open bar : non-filtered. Closed bar : filtered. Dotted line shows the JP or USP-defined limit of particulate counts in large volume injections. Data represent the mean \pm SEM $(\mathrm{n}=5) .{ }^{*} \mathrm{P}<0.05$, ${ }^{* *} \mathrm{P}<0.01$ vs. non-filtered (Paired student's ttest). in the injection fluid leads to the serious complications including pulmonary embolism ${ }^{15)}$ and infusion phlebitis ${ }^{16,17)}$. In general, the particulates that exceed $8 \mu \mathrm{m}$ in size are considered to be trapped by lung tissues which may cause pulmonary granulomas. On the other hand, most of the particulates were removed by passing through the present infusion set with an in-line filter, in which $98 \%$ of the particulates were removed. Therefore, the use of the present infusion set is desirable in case of preparing intravascular infusion fluids from large ampoules.

Etoposide is an anticancer agent used for small cell lung cancer and various other neocarcinomas ${ }^{18)}$. Because of the poor solubility in water, this agent has been formulated in a mixture of alcohols and surfactants ${ }^{19}$. Intravenous administration of the etoposide solution is allowed only after dilution with a proper infusion fluid. According to the instruction of the package insert, the formulation is diluted before injection with either $5 \%$ dextrose or $0.9 \%$ sodium chloride to give a final concentration of 0.2 to $0.4 \mathrm{mg} / \mathrm{mL}$, and should be slowly infused. If the concentration of etoposide is higher than $0.4 \mathrm{mg} / \mathrm{mL}$, crystalline precipitation may frequently occur. The etoposide concentration prepared in the present study was $0.52 \mathrm{mg} / \mathrm{mL}$, thus the compound easily 


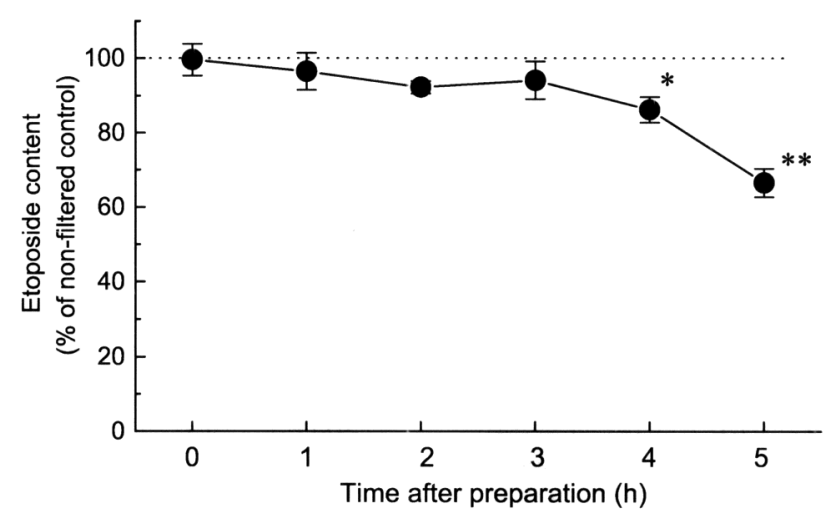

Fig. 5. Changes in Etoposide Content in Solution Collected through the New Infusion Set at Various Times after Dilution of Etoposide Injection with Saline. Etoposide injection $(26 \mathrm{mg} / \mathrm{mL})$ was diluted with $50 \mathrm{~mL}$ saline at the final concentration of $0.52 \mathrm{mg} / \mathrm{mL}$ and the solution was collected through the conventional (without in-line filter) intravenous infusion set or the new infusion set equipped with an in-line filter. The concentration of etoposide was determined by spectrophotometrically at an O.D. of $282 \mathrm{~nm}$. Each point represents the mean $\pm \mathrm{SEM}(\mathrm{N}=5) .{ }^{*} \mathrm{P}<0.05,{ }^{*} \mathrm{P}<0.01$ vs. nonfiltered at the respective time points (Student's t-test).

Plasma extravasation

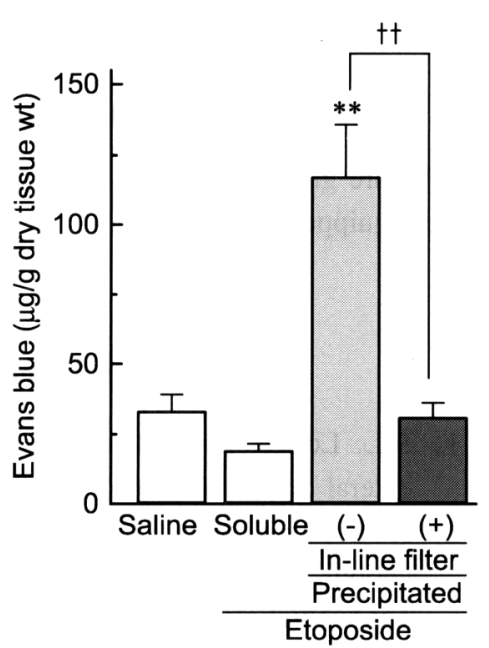

Tissue water content

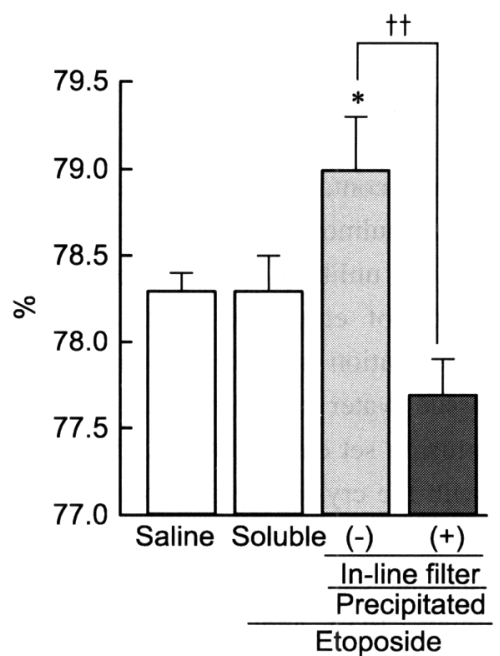

Fig. 6. Prevention by the use of the New Infusion Set Incorporated with an in-line Filter from Plasma Extravasation and Edema in Lungs of Rats Associated with Precipitates-containing Etoposide Solution. Rats were injected intravenously with the mixture of Evans blue dye $(20 \mathrm{mg} / \mathrm{mL})$ and precipitated or non-precipitated etoposide solution $(5 \mathrm{mg} / \mathrm{kg})$. At $10 \mathrm{~min}$ after injection, plasma extravasation was assessed by measuring the amount of Evans blue dye in lung tissues. Edema was assessed by measuring tissue water content. Each column represents the mean \pm SEM of 4-6 animals. ${ }^{*} \mathrm{P}<0.05,{ }^{* *} \mathrm{P}<0.01$ vs. saline (Dunnett's test), ${ }^{\dagger} \mathrm{P}<0.01$ (Student's t-test).

precipitates as early as $2 \mathrm{~h}$ after dilution with saline in 1 out of 5 lots. The number of precipitates exceeding $10 \mu \mathrm{m}$ in size was far beyond the limit $(25$ counts $/ \mathrm{mL})$ provided by JP and USP. As observed in case of glycyrrhizin solution, most of the precipitates were eliminated by passing through the new infusion set, although the concentration of etoposide in the filtrates was significantly lowered by $13.8 \%$ and 34.5 $\%$ at $4 \mathrm{~h}$ and $5 \mathrm{~h}$ after dilution, respectively. Thus, it is likely that the efficacy of the filtrates of precipitated etoposide solution is reduced.

It has been reported that systemic embolism associated with the crystalline precipitation occurs during total par- 


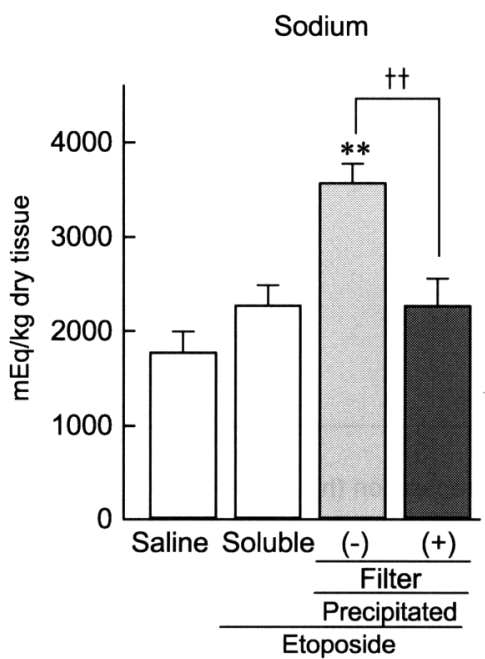

Potassium

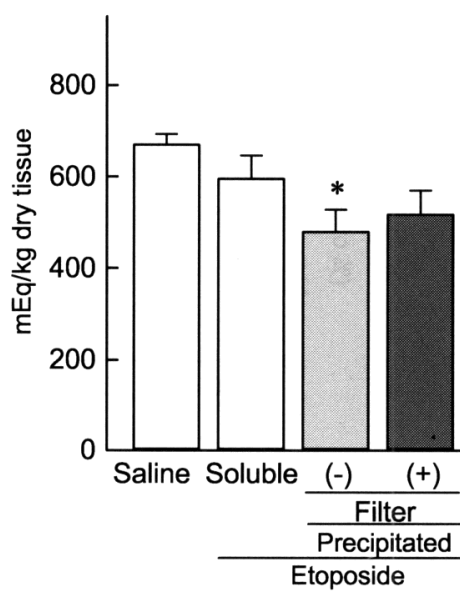

Fig. 7. Prevention by the Use of the New Infusion Set Incorporated with an in-line Filter from Pulmonary Edema in Rats Associated with Precipitates-containing Etoposide Solution, as Assessed by Changes in Tissue Contents of Electrolytes. The contents of tissue electrolytes were determined by an atomic absorption spectrophotometry. Each column represents the mean \pm SEM of 4-6 animals. ${ }^{*} \mathrm{P}<0.05,{ }^{* *} \mathrm{P}<0.01$ vs. saline (Dunnett's test), ${ }^{\dagger \dagger} \mathrm{P}<$ 0.01 (Student's t-test).

enteral nutrition ${ }^{20-22)}$. Although the case is rare, this may cause fatal complications. In the present study, the intravenous injection of precipitates-containing etoposide solution caused a marked increase in pulmonary vascular permeability and edema in rats. It is unlikely that the pulmonary edema is due to the action of etoposide itself, since the freshly prepared etoposide solution had no influence on the vascular permeability, tissue water or electrolytes contents. The use of the present infusion set enabled to avoid such adverse events associated with the crystalline precipitates.

Although the use of in-line filter is not recommended for the prevention of intravascular catheter-related infection according to CDC guideline ${ }^{23}$, FDA and ASPEN have proposed that the in-line filter or final filter is essential to remove the particulate matters or crystalline precipitates thus should be used routinely ${ }^{24,25}$. In fact, there have been several clinical reports showing the benefits of the use of the in-line filter in reducing the incidence of serious complications ${ }^{26,27}$. However, the use of in-line filter in the infusion line is not always common because of the medical expenses. The present infusion set, in which an in-line filter with $5 \mu \mathrm{m}$ in pore size is included beforehand, has minimum risk of infection. Moreover, it is not expensive, although the new product has not yet been commercially available. Thus, the present newly manufactured infusion set will be potentially useful during intravenous fluid therapy from the view points of safety management and medical cost, particularly when infusion fluids are prepared from glass ampoule products or contain water-insoluble medicines.

\section{Acknowledgement}

We are grateful to Nipro Co. for the supply of the in-line filter-equipped infusion set.

\section{References}

1) R.L. Longe, Particulate contamination in selected parenteral drugs, Can. Anaesth. Soc. J., 27, 62-64 (1980).

2) K. Carbone-Traber, C. Shanks, Glass particle contamination in single dose ampoules, Anesth. Anal., 65, 1361-1363 (1986).

3) T. Sendo, M. Hirakawa, K. Makino, K. Nakashima, Y. Kataoka, R. Oishi, Particulate contamination of lyophilized amphotericin B preparation during reconstitution process, J. Clin. Pharm. Ther., 26, 87-91 (2001).

4) L.A. Trissel, J.F. Martinez, M. Simmons, Compatibility of etoposide phosphate with selected drugs during simulated Y-site injection, J. Am. Pharm. Assoc., 39, 141-145 (1999).

5) K. Tsuji, A.R. Lewis, Evaluation of acceptance criteria for particulate limits for small-volume parenteral products, J. Pharm. Sci., 67, 50-55 (1978).

6) J.E. Dimmick, K.E. Bove, A.J. McAdams, G. Benzing, Fiber embolization a hazard of cardiac surgery and catheterization, New Engl. J. Med., 292, 685-687 (1975).

7) S.J. Turco, N.M. Davis, Detrimental effects of particulate matter on the pulmonary circulation, J. Am. Med. 
Assoc., 217, 81-82 (1971).

8) C. Munsxh, F. Rosenfeldt, V. Chang, M. Newman, B. Davis, Absence of particle-induced coronary vasoconstriction during cardioplegic infusion : is it desirable to use a microfilter in the infusion time?, J. Thorac. Cardiovasc. Surg., 101, 473-480 (1991).

9) B.T. Mckinnon, K.E. Avis, Membrane filtration of pharmaceutical solutions, American J. Hosp. Pharm., 50, 1921-1936 (1993).

10) The United States Pharmacopeia (USPXXIII) Rockville, MD: The United States Pharmacopenial Convention, 1816 (1995).

11) T. Sendo, K. Otsubo, A. Hisazumi, R. Oishi, Particle contamination in contrast media induced by disposable syringes, J. Pharm. Sci., 84, 1490-1491 (1995).

12) Y. Itoh, T. Sendo, T. Hirakawa, T. Goromaru, S. Takasaki, H. Yahata, H. Nakano, R. Oishi, Sensory nerve peptides rather than mast cell histamine are involved in paclitaxel hypersensitivity reactions, Am. J. Resp. Crit. Care Med., 169, 113-119 (2004).

13) R.K. Dhiman, Y.K. Chaela, Herbal medicines for liver diseases, Digest. Dis. Sci., 50, 1807-1812 (2005).

14) P.M. Kempen, E. Sulkowski, R.A. Sawyer, Glass ampoules and associated hazards, Crit Care Med., 17, 812-813 (1989).

15) W.E. Stebbens, H.W. Florey, The behavior of intravenously particles observed in chambers in rabbit's ears, Quart. J. Exp. Physiol., 45, 252-264 (1960).

16) F.A. Furgang, Glass particles in ampoules, Anesthesiol., 41, 525 (1974).

17) N.J. Shaw, E.G.H. Lyall, Hazards of glass ampoules, Brti. Med. J., 29, 13-90 (1985).

18) E.F. Smit, D.N. Carney, P. Hurford, D.T. Sleijfer, P.E. Postmos, Phase II study of oral etoposide in elderly patients with small cell lung cancer, Thorax, 44, 631-633 (1989).

19) P.I. Clark, M.L. Slevin, The clinical pharmacology of etoposide and teniposide, Clin. Pharmacokinet., 12, 223-252 (1987).

20) J.S. Reedy, J.E. Kuhlman, M. Voytovich, Microvascular pulmonary emboli secondary to precipitated crystals in a patient receiving total parenteral nutrition : a case report and description of the high-resolution CT findings, Chest, 115, 892-895 (1999).

21) S.E. Hill, L.S. Heldman, E.D. Goo, P.E. Whippo, J.C. Perkinson, Fatal microvascular pulmonary emboli from precipitation of a total nutrient admixture solution, $J$. Parent. Ent. Nut., 20, 81-87 (1996).

22) T. McNearney, C. Bajaj, M. Boyars, J. Cottingham, A. Haque, Total parenteral nutrition associated crystalline precipitates resulting in pulmonary artery occlusions and alveolar granulomas, Digest. Dis. Sci., 48, 13521354 (2003).

23) N.P. O'Grady, M. Alexander, E.P. Dellinger, J.L. Gerberding, S.O. Heard, D.G. Maki, H. Masur, R.D. McCormick, L.A. Mermel, M.L. Pearson, I.I. Raad, A. Randolph, R.A. Weinstein, Guidelines for the prevention of intravascular catheter-related infections. Centers for Disease Control and Prevention, Morbid. Mortal. Weekly Rep. : Recommend. Rep./Surveil. Sum., 51(RR10), 1-29 (2002).

24) M.M. Lumpkin, Safety alert: hazards of precipitation associated with parenteral nutrition, Am. J. Hosp. Pharm., 51, 1427-1428 (1994).

25) National Advisory Group on Standards and Practice Guidelines for Parenteral Nutrition, Safe Practices for Parenteral Nutrition Formulations, J. Parent. Ent. Nut., 22, 49-66 (1998).

26) K.H. Falchuk, L. Peterson, B.J. McNeil, Microparticulate-induced phlebitis. Its prevention by in-line filtration, New Engl. J. Med., 312, 78-82 (1985).

27) R.A. Van Lingen, W. Baerts, A.C. Marquering, G.J. Ruijs, The use of in-line intravenous filters in sick newborn infants, Acta Paediat., 93, 658-662 (2004). 